\title{
A Study Of Subclinical Mastitis in Two Herds, One Managed Organically, the Other Conventionally, and the Effect of Different Management Strategies
}

\author{
Alan ThatCher ${ }^{1}$, KIRO Petrovski $^{2 *}$, NATAlia MARTIN ${ }^{1}$
}

Key words: mastitis, organic, bulk milk somatic cell count, management

\begin{abstract}
Mastitis in two herds managed as a comparison between organic and conventional dairy farming systems was monitored for 9 years utilising regular bacterial culture of milk samples, individual and bulk somatic cell counts and observation by farm staff. The most important isolates in pure cultures were coagulase-negative staphylococci, Staphylococcus aureus, Streptococcus uberis, and the common contaminant Bacillus spp. Positive cultures were generally not associated with subclinical mastitis. The aim of the project was to develop strategies for the control of mastitis in organic cows without the use of antibiotics. Within a set of key control measures, two management strategies were trialled, one of which reduced the prevalence of subclinical mastitis to very low levels.
\end{abstract}

\section{Introduction}

Between 2001 and 2011, Massey University set up its Dairy Cattle Research Unit (DCRU) as a system comparison between organic and conventional farming. The farm was a seasonal producer with calving from late July until mid-October. All cows were dried off by the end of May, the exact date depending largely on pasture availability.

The DCRU was split into two similar units. The organic unit carried typically 44 cows $(2.27 \mathrm{cows} / \mathrm{Ha})$ and the conventional 51 (2.39cows/Ha), respectively. From August 2006, all organic dairy suppliers to Fonterra NZ Ltd were required to meet the standards set by the USDA National Organics Program. Each of the two units was managed individually according to "best practice" for its particular type of management system. The project has been described in detail by Kelly et al (2006).

Mastitis control for the conventional herd was based on New Zealand's Seasonal Approach to Managing Mastitis (SAMM) Plan, a nationwide scheme administered by the National Mastitis Advisory Committee. Control in the organic herd was based on the same principles excluding (since 2005) the use of antibiotics. In particular, emphasis was placed on key measures: vigilance, separation of infected cows, a clean stressfree environment, high quality teat spraying, post-milking stripping of high somatic cell count (SCC) quarters, appropriate treatment, supportive therapy and appropriate culling. An iodine-based teat spray was used on both herds post milking. Financial penalties apply to bulk milk submitted with a SCC exceeding 400,000 cells per $\mathrm{mL}$.

The predominant major mastitis pathogens in New Zealand are Streptococcus uberis and Staphylococcus aureus. The most commonly isolated minor pathogens are coagulase-negative staphylococci (CNS) (Petrovski et al, 2011). Prevalence of subclinical mastitis (SCM) is an important pre-requisite to estimating the cost of mastitis to the dairy industry (Petrovski et al, 2006). A previous paper reported on mastitis in the two herds from 2003 to 2007 (Thatcher et al, 2008). This paper presents the prevalence of SCM and describes the bulk milk somatic cell count (BMSCC) of both herds from the 2006/07 season to the end of the project in 2011.

\section{Material and methods}

In November 2003, a sampling regime began whereby milk from each quarter of each cow in both herds was submitted for bacterial culture. Sampling occurred 4 times per season; at calving, 14 days after calving, at mid lactation and at drying off. Culture and classification of organisms was carried out by New Zealand Veterinary Pathology Ltd. Additional data was gathered from monthly individual somatic cell counts (ISCC) carried out by the Livestock Improvement Corporation as part of routine herd testing and daily BMSCC

\footnotetext{
${ }^{1}$ Institute of Veterinary Animal and Biomedical Sciences, Massey University, Palmerston North, New Zealand. www.massey.ac.nz. Email A.Thatcher@massey.ac.nz N.Martin@massey.ac.nz

${ }^{2}$ School of Veterinary and Animal Sciences, University of Adelaide, Roseworthy, Australia. www.adelaide.edu.au *Author for correspondence: kiro.petrovski@adelaide.edu.au
} 
provided by Fonterra. DCRU staff carried out regular California Mastitis Tests (CMT) on known or suspected infected cows.

In February 2008 a new manager was appointed. The two managers covering the period from 2006 to 2011 had different approaches within the framework of control strategies. These tended to reflect the strategies adopted by commercial organic farmers:

Manager 1 (May 2006 - December 2007): Emphasis on maximising saleable milk. Vigilance was vital for this to be effective as it involved adding milk from cows with higher ISCC to the bulk supply when BMSCC was low and withdrawing milk from those cows when it was high. The risk was that miscalculation may result in an elevated BMSCC penalty. Perhaps more importantly, the cows with higher ISCC were a risk to uninfected cows unless kept separated (logistically difficult at DCRU).

Manager 2 (February 2008 - May 2011): Emphasis on minimising the BMSCC from the middle of the 2008/09 season. This involved initially a higher culling rate and volume of milk discarded but minimised the risk of spread of contagious organisms. Segregation of known infected cows was undertaken as far as was practical and a small number of chronically infected quarters were dried off. The management changes are described in detail by Thatcher et al (2010).

Somatic cell count data were assessed by repeated Analysis of Variance using the MIXED function in SAS 9.3 (Cary Inc, USA). All other comparisons were made using the student t-test.

\section{Results}

The majority of quarters culture positive to S. uberis or CNS did not develop chronic SCM, as determined by concurrent ISCC or a positive CMT. There was a moderate association between a positive culture for $S$. aureus and a chronically elevated ISCC.Numbers of cows affected by SCM are presented in Table 1.

Table 1: Number of cows with an elevated individual cow somatic cell count $(>150,000$ cells/mL for cows or 120,000 cells $/ \mathrm{mL}$ for heifers) two or more times per season

\begin{tabular}{l|c|c|c|c|c} 
Season & $2006 / 07$ & $2007 / 08$ & $2008 / 09$ & $2009 / 10$ & $2010 / 11$ \\
\hline Organic & 21 & 16 & 16 & 4 & 12 \\
\hline Conventional & 14 & 16 & 13 & 6 & 9
\end{tabular}

Average seasonal BMSCC for both herds is presented in Table 2. From $2006-2008$ the organic herd BMSCC exceeded the penalty level of 400,000 cells $/ \mathrm{ml} 10$ times and the conventional herd 6 times. From 2009 - 2011 the penalty level with the organic herd was exceeded once and the conventional herd never. For the $2009 / 10$ season, the organic herd achieved the $44^{\text {th }}$ lowest average BMSCC for Fonterra suppliers, covering some $90 \%$ of dairy farms in New Zealand. The conventional herd was the $56^{\text {th }}$ lowest. BMSCC of both herds rose during the summer of 2010/11 associated with an increase in the prevalence of major pathogens but fell again towards the end of the season (Table 3). The season was also characterised by a substantial rise in both the prevalence of CNS and Bacillus species recovered from milk samples. CNS became very prevalent in the organic herd but only very few cases were associated with a rise in ISCC. There was no relationship with the presence of Bacillus and a raised SCC in the gland from which it was recovered but there was a strong association with the presence of CNS in the same sample.

Table 2: Average bulk milk somatic cell count (BMSCC) in thousands per $\mathrm{mL}$ and the number of BMSCC penalties ( $>400,000$ cells $/ \mathrm{mL}$ ) for each herd by season.

\begin{tabular}{l|c|c|c|c|c} 
Season & $2006 / 07$ & $2007 / 08$ & $2008 / 09$ & $2009 / 10$ & $2010 / 11$ \\
\hline Organic & 233 & 226 & 148 & 67 & 145 \\
\hline Conventional & 194 & 195 & 154 & 75 & 139 \\
\hline $\begin{array}{l}\text { BMSCC penalties } \\
\text { organic, conventional }\end{array}$ & 3,2 & 4,2 & 3,2 & 0,0 & 1,0
\end{tabular}


Although the project finished in May 2011, the organic herd was retained for a further $1 \frac{1}{2}$ seasons. Average BMSCC for the 2011/12 season was 156,000. Average BMSCC from the start of the 2012/13 season until the herd was disbanded in January 2013 was 126,000 and there was one penalty for this entire period.

Table 3: Number of bacteriologically positive cows (any sample) associated with an increased individual cow somatic cell count $(>150,000$ cells $/ \mathrm{mL}$ for cows, 120,000 cells/mLfor heifers) in each herd, by season

\begin{tabular}{l|c|c|c|c}
\multirow{2}{*}{ Season } & \multicolumn{2}{|c|}{$2009 / 10$} & \multicolumn{2}{c}{$2010 / 11$} \\
\hline & organic & conventional & organic & conventional \\
\hline Staphylococcus aureus & 0 & 1 & 4 & 2 \\
\hline Streptococcus uberis & 0 & 2 & 6 & 2 \\
\hline $\begin{array}{l}\text { Streeptococcus } \\
\text { dysgalactia }\end{array}$ & 0 & 0 & 1 & 3 \\
\hline $\begin{array}{l}\text { Coagulase-negative } \\
\text { staphylococci }\end{array}$ & 4 & 4 & 6 & 3
\end{tabular}

While between 2003 and 2007 typically $2-4$ organic and $1-3$ conventional cows were culled for chronic mastitis per season, a total of 9 organic and 6 conventional cows were culled for this reason between January 2009 and May 2010 (encompassing 11/2 seasons). One cow was culled for mastitis from each herd during the 2010/11 season, thus the average cull rate between 2008 and 2011 was not significantly different from the period 2003 to 2007.

\section{Discussion}

The previous paper identified control of $S$. aureus as the most important factor in managing mastitis in a pastoral-based organic herd, while environmental pathogens were easier to control with adequate management of the cow's surroundings. The difficulty in eliminating $S$. aureus once well established in the udder means BMSCC may remain relatively high despite minimal spread of infection between cows. Management of BMSCC focused on the relatively small proportion of chronic SCM cases, identified by ISCC and monitored on a daily basis using the California Mastitis Test. Initial changes in management procedures targeting the incidence of S. aureus in the organic herd were instigated at the start of the 2006/07 season. Although there was a decline in the incidence of $S$. aureus and CNS recovered from milk samples and in the incidence of clinical mastitis in the organic herd, BMSCC remained relatively high.

From late in the 2008/09 season the removal of chronically infected cows and drying off a limited number of selected quarters resulted in the incidence of $S$. aureus detected in milk samples falling to very low levels. It was also characterised by a marked decline in the prevalence of subclinical infections. The 2010/11 season was similarly characterised by a low prevalence of S. aureus. However, the summer of 2010/11 was unusually wet and the rise in BMSCC of both herds at this time may have been due to a decline in the effectiveness of teat spraying typical of wet weather. Detection of Bacillus species in milk samples tends to indicate teats contaminated with mud and an increase in the incidence of $S$. uberis and S. dysgalactiae may have resulted from that. However, presence of Streptococci in samples remained relatively low (<5\% of quarters from day 14 , both herds) indicating that measures to control faecal contamination of teats at critical times of year remained largely effective. The prevalence of SCM was not increased in quarters with Bacillus isolates indicating that intramammary infection was unlikely to be caused by this organism. The strong association between the concurrent presence of Bacillus species and CNS further points to teat spraying issues, particularly mid-season. Additionally, as the project was coming to an end, vigilance of farm staff may have declined.

\section{Conclusion}

It has been demonstrated that removal and/or segregation of high ISCC cows along with limited drying off of chronically infected quarters while maintaining strict measures to prevent spread of infection has a longer term benefit in reducing the prevalence of SCM and the likelihood of BMSCC penalties. Thus, instituting these measures can enable good control of mastitis in organic herds 


\section{Acknowledgements}

The project was funded by DairyNZ. Assistance from the staff of DCRU and Kim Fraser is gratefully acknowledged.

\section{References}

Kelly T., Butcher N., Harrington K., Holmes C., Horne D., Kemp P., Palmer A., Quinn A., Shadbolt N., Thatcher A. (2006): Organic-Conventional dairy systems trial in New Zealand: four years results. ISOFAR. http://orgprints/4392/

Petrovski KR, Trajcev M, Buneski G. (2006): A review of the factors affecting the costs of bovine mastitis. J South Afr VA 77: 52-60.

Petrovski, K. R., Williamson N. B., Lopez-Villalobos N., Parkinson T. J., Tucker I. G.. (2011). Culture results from milk samples submitted to veterinary diagnostic laboratories from August 2003 to December 2006 in New Zealand. New Zealand Veterinary Journal 59(6):317-322.

Thatcher, A; Petrovski, K; Holmes, C; Dowson, K; Kelly, T and McLeod, K (2008): A longitudinal study of mastitis on an experimental farm with two herds, one managed organically, the other conventionally. ISOFAR. http://orgprints/11559/

Thatcher, A., Petrovski, KR. and Fraser, K.(2010): Influence of management techniques on the levels of mastitis in an organic dairy herd. Proceedings of the New Zealand Society of Animal Production, Volume 70, pp 316-318 